\title{
Entrevista à Professora Doutora Constância Lima Duarte
}

Constância Lima Duarte graduou-se em Letras pela Universidade Federal de Minas Gerais, realizou o Mestrado na Pontifícia Universidade Católica do Rio de Janeiro e defendeu o Doutorado na Universidade de São Paulo com a tese ñNísia Floresta: vida e obraò, conduzida sob a supervisão de Nádia Battella Gotlib. Lecionou na Universidade Federal do Rio Grande do Norte e atualmente é professora da Universidade Federal de Minas Gerais, onde integra o Centro de Estudos Literários do qual foi diretora. Pesquisadora do $\mathrm{CNPq}$, é membro do Núcleo de Estudos Interdisciplinares da Alteridade (NEIA) e coordenadora dos grupos de pesquisa ñLetras de Minasò e ñMulheres em Letrasò. Desenvolve pesquisas junto ao Acervo de Escritores Mineiros, da UFMG, onde colheu subsídios para o Dicionário Bibliográfico de escritores mineiros (2010). Especialista em literatura de expressão feminina, é autora de vários estudos sobre a pioneira Nísia Floresta, de quem editou recentemente o opúsculo Direitos das mulheres, injustiça dos homens (2019) e reuniu Inéditos e Dispersos (2009). Publicou o Dicionário de Escritoras Portuguesas (2009), o dicionário ilustrado Imprensa feminina e feminista no Brasil, século XIX (2016) e participou da organização de diversos volumes coletivos reunindo estudos de gênero e representação, tais como Escritoras de ontem e hoje (2012), Maria Firmina dos Reis: faces de uma precursora (2018), Poéticas do feminino (2018), Mulheres em Letras (2019), Poéticas do devirmulher: ensaios sobre escritoras brasileiras (2019).

Soletras: Poderia contar um pouco sobre a sua trajetória de pesquisadora da imprensa vinculada à área de Letras? Como surgiu seu interesse pelos periódicos?

Duarte: Como professora de Literatura Brasileira, sempre me incomodou a ausência de nomes de mulheres nos livros de história literária, nas antologias e manuais de literatura. E foi procurando pelas primeiras escritoras que me deparei com os periódicos ñfemininosò, onde elas publicavam seus poemas e textos em prosa. Na época, achei interessante constatar que foram os jornais, e não os livros, os primeiros veículos

\footnotetext{
${ }^{1}$ Professora Livre Docente pela Unicamp atua junto ao Programa de Pós-Graduação em Teoria e História Literária (PGTHL), Instituto de Estudos da Linguagem, da Unicamp. E-mail: orna@ unicamp.br Orcid: https://orcid.org/0000-0002-3322-3927
} 


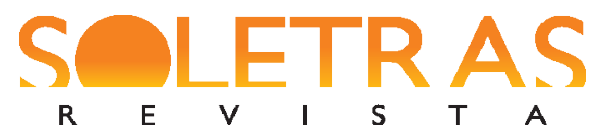

utilizados pelas escritoras, e que eles se tornaram valiosos espaços de divulgação e de resistência. Outra constatação foi observar que literatura, imprensa e consciência feminista surgiram praticamente ao mesmo tempo no Brasil, nas primeiras décadas do século XIX. Quando as primeiras mulheres tiveram acesso ao letramento, imediatamente se apoderaram da leitura, que por sua vez as levou à escrita e à crítica. E independente de serem poetisas, ficcionistas, jornalistas ou professoras, a leitura lhes deu consciência do estatuto de exceção que ocupavam no universo de mulheres analfabetas, da condição subalterna a que o sexo estava submetido, e propiciou o surgimento de escritos reflexivos e engajados, tal a denúncia e o tom reivindicatório que muitos deles ainda hoje contêm.

Soletras: A que atribui a falta de atenção ao periodismo por parte da historiografia da literatura brasileira?

Duarte: Creio que são muitos os fatores envolvidos, como, por exemplo, a desvalorização do veículo e o desconhecimento de seu papel na construção cultural da sociedade. Mas o principal fator deve ser nosso tradicional desprezo pela história e por tudo que envolve o passado. Falta-nos a cultura da preservação e, por isso, sobra o memoricídio, isto é, o sistemático apagamento da memória cultural. No caso das mulheres isso ocorre (ou ocorreu) com muito mais virulência, pois não só seus textos literários foram ignorados, como também sua produção jornalística, sua história de luta e resistência. Os nomes das pioneiras só começaram a aparecer após o trabalho de resgate feito por um grupo de pesquisadoras, nas duas últimas décadas. E se as escritoras estiveram invisíveis na história literária dos séculos XVIII e XIX, isso se deve ao corporativismo masculino, pois durante muito tempo só os homens ocuparam os espaços de poder. E entre um autor e uma autora, os editores, jornalistas, críticos e pesquisadores, sempre preferiram divulgar o escritor. Enfim, foram muitos vícios da sociedade patriarcal que as mulheres tiveram que enfrentar quando deixaram de ser apenas leitoras e se tornaram também escritoras. 


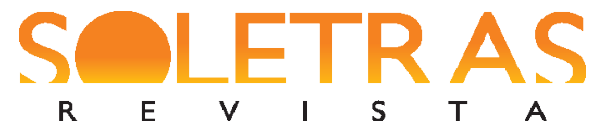

Soletras: Que critérios utilizou em seu trabalho de elaboração do dicionário ilustrado para estabelecer o corpus dos periódicos considerados femininos e feministas?

Duarte: Após um amplo levantamento dos periódicos que tinham como público alvo as mulheres, realizado em acervos e arquivos de bibliotecas, em livros e, posteriormente, em sites da internet, a segunda etapa consistiu em observar não mais a quem se dirigia a publicação, mas como se dirigia às leitoras. E logo ficou evidente duas tomadas de posição bem distintas: uma, que endossava o status quo, ou seja, que reforçava os tradicionais papéis de esposa carinhosa, boa dona de casa e filha obediente, além da imagem de mulher vaidosa e preocupada com a moda. E outra, que denunciava a opressão e exigia a ampliação de direitos civis e políticos. Por uma questão didática, chamei os primeiros de ñfemininosò e os demais de ñfeministasò. Mas é importante ressaltar que tanto mulheres como homens participaram das duas categorias de periódicos, e, muitas vezes, encontramos artigos incrivelmente revolucionários ao lado de outros conservadores, no mesmo periódico. Também é preciso destacar que ambas as modalidades tiveram participação decisiva na formação intelectual da mulher, e na construção cultural e discursiva de sua identidade.

$\mathrm{Na}$ organização do dicionário, os periódicos foram apresentados por ordem cronológica de publicação, e cada verbete contém, sempre que possível, o subtítulo do jornal ou revista, o nome do editor ou da editora, a cidade de origem, a tipografia, as datas do primeiro e último números, a proposta editorial, o formato gráfico e a relação dos principais colaboradores e colaboradoras. Informo ainda quais foram os exemplares examinados, onde se encontram, e referências bibliográficas. A extensão dos verbetes varia principalmente em função de se ter tido ou não acesso aos originais e a fontes de informação. Enquanto alguns já possuem um volume razoável de estudos, outros podem ser conhecidos apenas pelo registro que receberam de outros pesquisadores.

Soletras: Além do conteúdo cultural, o levantamento das publicações periódicas desvendou uma participação das mulheres jornalistas no campo político. $O$ que o 


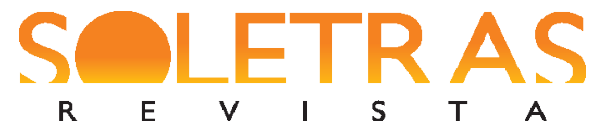

estudo da imprensa permite conhecer a respeito da perspectiva política nos escritos femininos?

Duarte: O estudo da imprensa nos permite saber que existiram mulheres no século XIX antenadas às questões políticas de seu tempo, e que usaram a imprensa para se manifestar e se posicionar politicamente, a favor ou contra a Monarquia, a Revolução Farroupilha, a Constituinte, a Abolição ou a República. Dentre muitos títulos, lembro: Belona Irada contra os Sectários de Momo (1833-1834) e Idade dôOuro (1833), ambos de Porto Alegre, dirigidos pela escritora Maria Josefa Barreto; República das Moças (1879), O Abolicionista do Amazonas (1884) e Ave Libertas (1885), cujos títulos já dizem sobre o posicionamento das editoras. Outros se empenharam em conscientizar as leitoras de seus direitos à educação, à propriedade, ao voto e ao trabalho, e contestaram o mandonismo patriarcal e o comportamento domesticado das mulheres, como $O$ Sexo Feminino (1873-1889), A Mulher (1881-1883), A Mensageira (1897-1900) e O Escrínio (1898-1910) etc. etc...

Soletras: O mapeamento do periodismo feminino no Brasil indicou que a existência de uma rede de apoio e cooperação entre as publicações foi fundamental para garantir espaço às escritoras jornalistas. A rede de contatos e intercâmbios se limitava ao país ou possuía caráter transnacional?

Duarte: A partir de 1870, os órgãos feministas se multiplicam por todo o país, contribuindo para minimizar o isolamento das mulheres, divulgar as conquistas e realizar uma espécie de intercâmbio intelectual entre eles, e entre elas, as redatoras. Ao se articularem, as jornalistas estabeleceram uma espécie de rede de apoio, que divulgava os novos jornais e transcreviam notícias sobre os avanços da situação feminina, no Brasil e nos outros países. Dou um exemplo emblemático: em 1880, duas jovens pernambucanas ï Maria Augusta Generosa Estrela e Josefa Águeda Felisbella Mercedes ï foram cursar medicina no New York Medical College and Hospital for Women, e lá criaram o periódico A Mulher (1881-1883), que circulou em Nova York e em Recife, e 


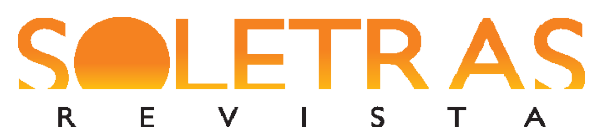

trazia textos em inglês e espanhol, além de português, dedicados a incentivar as jovens a fazerem o curso superior, principalmente.

Soletras: Quanto à presença da literatura no periodismo do século XIX, notou diferença entre as publicações da corte e as das demais províncias?

Duarte: Sinceramente, não muita diferença, o que também foi motivo de surpresa. Em pequenas cidades do interior do Ceará, da Bahia, ou de Minas Gerais, e mesmo em pequenas capitais, como Manaus, Fortaleza e Natal, circularam periódicos que estavam em sintonia com a estética romântica dominante, e também com as novas ideias sobre os avanços alcançados pelas mulheres naquele momento histórico.

Soletras: De que modo a questão da autoria feminina se manifestou nos periódicos do século XIX?

Duarte: Como os jornais se constituíram em espaço privilegiado para a divulgação da literatura, e a maioria das escritoras publicaram antes em suas páginas, é possível encontrar aí o nascedouro de muitas vocações literárias. Mas lembro um detalhe importante: assinar uma publicação naquele tempo representava um ato de coragem, pois significava tornar públicas suas ideias... E nem toda mulher tinha coragem para tanto. Por isso, nessa época, muitas escritoras usaram pseudônimos (e não só no Brasil), visando preservar sua imagem e proteger seu círculo mais íntimo da pressão social, advinda da exposição pública. Havia uma ñcensura no arò, uma oposição implícita contra a mulher que escrevesse. $\mathrm{O}$ anonimato também permitiu às mulheres escamotear o conflito que devia ser motivo de angústia para muitas: proteger-se e ter vida privada, ou assinar uma obra e expor-se pela publicação de suas ideias. Entre o ideal feminino e a imagem de artista havia, nesses tempos, uma incompatibilidade quase inconciliável. Virgínia Woolf sugere, inclusive, que muitos daqueles ñAnônimosò, que escreveram tantos poemas, romances e novelas, devam ter sido, na verdade, ñAnônimasò, no 


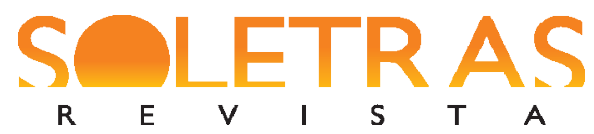

feminino, o que pode bem ser possível. Mas, apesar do preconceito, muitas não se intimidaram e assinaram suas obras, como Josefa Barreto, a poetisa mineira Beatriz Brandão, a feminista Josefina Álvares de Azevedo, e ainda Carmen Dolores, Júlia Lopes de Almeida e Gilka Machado, entre muitas outras.

Soletras: Em sua opinião, que perspectivas futuras a investigação em fontes primárias lança para os estudos literários?

Duarte: Penso que os estudos literários têm muito a ganhar com a pesquisa em fontes primárias, porque está lá ï encantado nos acervos de antigas bibliotecas ï um manancial literário talvez ainda desconhecido da historiografia. Acredito que, uma vez descobertos, muitos periódicos devem propiciar novas reflexões acerca da tradição literária das mulheres, da profissionalização das primeiras jornalistas, do papel das revistas e jornais na ampliação do público leitor e na conscientização feminina. Também devem revelar os gêneros literários em voga e os avanços obtidos pelo segmento feminino na política educacional, entre outros aspectos.

Soletras: Observando a partir da imprensa, o que mudou na construção cultural e discursiva da identidade da mulher desde o século XIX até hoje?

Duarte: Penso que finalmente as diferenças identitárias existentes entre as mulheres estão sendo consideradas. E as lésbicas, as negras e as trans, cada uma está sendo vista e apresentada em sua especificidade. Porque não se pode mais falar em ñmulherò, mas em mulheres. Daí a urgência do fortalecimento do feminismo negro, que se diferencia por defender as necessidades e demandas relativas à mulher negra. Historicamente, o movimento feminista sempre privilegiou as pautas de mulheres brancas, heterossexuais, da classe média e alta, e universalizou a categoria mulher como se todas sofressem o mesmo tipo de opressão. O que não é verdade. No passado, enquanto as brancas estavam confinadas no espaço doméstico, as negras, por uma contingência social, na 


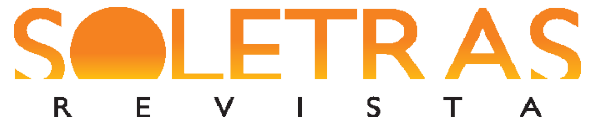

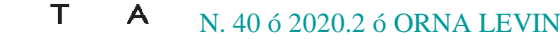

CONSTÂNCIA LIMA DUARTE

condição de mulheres escravizadas ou libertas, sempre estiveram no espaço público, lutando pela sobrevivência. A única verdade é que toda mulher ï independente da etnia, sexualidade e classe social $\ddot{i}$ sofre com o machismo, com a misoginia e com o falocentrismo ï os pilares do patriarcado.

Realizada em: 10 de julho de 2020. 